\title{
LZ-101, a novel derivative of danofloxacin, induces mitochondrial apoptosis by stabilizing FOXO3a via blocking autophagy flux in NSCLC cells
}

\author{
Yongjian Guo ${ }^{1}$, Yue Zhao ${ }^{2}$, Yuxin Zhou ${ }^{2}$, Xiaoqing Tang ${ }^{1}$, Zhiyu $\mathrm{Li}^{3}$ and Xiaotang Wang ${ }^{1}$
}

\begin{abstract}
Non-small-cell lung carcinoma (NSCLC) continues to be a vital disease worldwide for its high incidence and consequent mortality rate. In this study, we investigated the anti-cancer effect of LZ-101, a new derivative of danofloxacin, against non-small-cell lung cancer and the underlying mechanisms. In vitro, LZ-101 inhibited the viability of human non-small cell lung cancer cell lines. We demonstrated that LZ-101 induced mitochondrial-mediated apoptosis by increasing Bax/Bcl-2 ratio, loss of mitochondrial membrane potential $\left(\Delta \psi_{m}\right)$, release of cytochrome $c$ (Cyt c) and apoptosis-inducing factor (AIF) in A549 cells. Further research illuminated that LZ-101 induced apoptosis was related to the activation of FOXO3a/Bim pathway. Moreover, we found that LZ-101 increased the stability of FOXO3a by blocking autophagy-dependent FOXO3a degradation. However, inhibition of autophagosome formation abolished FOXO3a stabilization and apoptosis induced by LZ-101. In vivo, LZ-101 exerted a remarkable anti-tumor activity with high safety in xenograft model inoculated A549 tumor through the same mechanism as in our in vitro study. In conclusion, our findings indicated that LZ-101 induces mitochondrial apoptosis and stabilizes FOXO3a by blocking autophagy flux.
\end{abstract}

\section{Introduction}

Lung cancer is a leading cause of cancer-related mortality in a global perspective, of which non-small-cell lung carcinoma (NSCLC) has the highest risk of causing lung cancer-related deaths. Almost $80 \%$ of lung cancer-related deaths occur in patients with non-small-cell lung can$\mathrm{cer}^{1,2}$. Despite recent advances in therapeutic regimen, the curative effect is not so inspiring because of the poor

\footnotetext{
Correspondence: Xiaotang Wang (wangx@fiu.edu)

${ }^{1}$ Department of Chemistry and Biochemistry, Florida International University, Miami, FL, USA

${ }^{2}$ State Key Laboratory of Natural Medicines, Jiangsu Key Laboratory of Carcinogenesis and Intervention, China Pharmaceutical University, 24 Tongjiaxiang, 210009 Nanjing, The People's Republic of China

Full list of author information is available at the end of the article. These authors contributed equally: Yongjian Guo, Yue Zhao

Edited by G. Dewson
}

outcome $^{3}$. Consequently, it is indispensable to develop more effective therapies against lung cancer.

There are two major apoptosis pathways, the extrinsic and intrinsic (mitochondria-associated) pathways, in cytoplasm. Intrinsic apoptosis could be regulated via mitochondrial pathway characterized by the release of cytochrome $c$ (Cyt $c$ ) and activation of caspase ${ }^{4}$. The Bcl-2 family proteins, anti-apoptotic proteins (such as $\mathrm{Bcl}-2$ and $\mathrm{Bcl}-\mathrm{xL}$ ), pro-apoptotic proteins (such as Bax and Bak), and Bcl-2 homology 3-only (BH3-only) proteins (such as Bim, Bad, and Puma), play a crucial role in intrinsic apoptotic process. The apoptotic stimuli activate specific BH3-only proteins to engage anti-apoptotic proteins and release downstream pro-apoptotic proteins, leading to increased mitochondrial outer membrane permeability and eventually cell death induced by triggering caspase cascade $^{5}$. Subsequently, cytochrome $c$ is released from

\section{(c) The Author(s) 2019}

(c) (i) Open Access This article is licensed under a Creative Commons Attribution 4.0 International License, which permits use, sharing, adaptation, distribution and reproduction in any medium or format, as long as you give appropriate credit to the original author(s) and the source, provide a link to the Creative Commons license, and indicate if changes were made. The images or other third party material in this article are included in the article's Creative Commons license, unless indicated otherwise in a credit line to the material. If material is not included in the article's Creative Commons license and your intended use is not permitted by statutory regulation or exceeds the permitted use, you will need to obtain permission directly from the copyright holder. To view a copy of this license, visit http://creativecommons.org/licenses/by/4.0/. 
mitochondria into cytoplasm which can trigger the caspase cascade, leading to cell death. Bim acts as direct activators of Bax and Bak by interacting with them. Bim is also involved in p53-dependent and p53-independent apoptosis $^{6}$. Recent studies have implicated that Bim may serve as a potential target for anti-cancer chemotherapeutics since it plays an important role in apoptosis ${ }^{7,8}$.

The FOXO subfamily of transcription factors is evolutionarily conserved, including FOXO1, FOXO3a, FOXO4, and FOXO6 ${ }^{9}$. FOXO proteins can regulate multiple target genes involved in tumor suppression, such as Bim, FasL, p27kip1, cyclin D and GADD45 ${ }^{10-13}$. FOXO3a, the most important transcription factor in FOXO family, was phosphorylated by Akt at Thr32, Ser253, and Ser315, leading to FOXO3a translocate from nucleus to cytoplasm and is consequently degraded by proteasome ${ }^{14}$. The proteasome inhibitor MG132 increases the stability of FOXO3a and induces apoptosis in thyroid cancer cell ${ }^{15}$. In addition, studies have reported that FOXO3a is a substrate for autophagy ${ }^{16}$. This suggests that FOXO3a degradation depends not only on the proteasome pathway, but also on autophagy activation.

LZ-101 is a derivative of danofloxacin that has been developed specifically for veterinary use ${ }^{17}$. Danofloxacin has been widely used for the treatment for respiratory disease and urinary tract infections in animals, such as chicken and buffalo ${ }^{18,19}$. However, studies have shown that danofloxacin induces apoptosis by inducing oxidative stress in renal tubular cells, epithelial cell line (LLC-PK1). This study showed that danofloxacin exhibited apoptosisinducing effects. While the effect of danofloxacin derivative LZ-101 on apoptosis is still unclear. This study demonstrated that LZ-101 induced apoptosis in A549 human non-small-cell lung cancer cells and inhibited tumor growth with low systemic toxicity in BALB/c mice bearing A549 tumor through mitochondria-associated pathway by stabilizing FOXO3a via blocking autophagy flux. Our results showed that LZ-101 exhibits remarkable anti-tumor activity and is promising to serve as an effective candidate for the treatment of human non-smallcell lung cancer.

\section{Results}

\section{LZ-101 inhibited cell viability in human non-small-cell lung cancer cells}

The chemical structure of LZ-101 was shown in Fig. 1a. To evaluate the inhibitory effect of LZ-101 on human non-small-cell lung cancer cells including A549, H1299, and $\mathrm{H} 460$ cells, we investigated its effect on cell viability at different concentrations with varying lengths $(12,24$, or $48 \mathrm{~h}$ ) of treatment. The $\mathrm{IC}_{50}$ (the concentration of drug inhibiting $50 \%$ of cells) values for A549 cells were $13.95 \pm$ $2.24,8.61 \pm 0.75$, and $4.28 \pm 0.42 \mu \mathrm{M}$, respectively, after 12, 24, and $48 \mathrm{~h}$ treatment (Fig. $1 \mathrm{~b}$ ). Whereas, the $\mathrm{IC}_{50}$ values for $\mathrm{H} 1299$ were $44.47 \pm 6.54,18.47 \pm 0.86$, and $6.75 \pm 0.58 \mu \mathrm{M}$, respectively, after 12,24 , and $48 \mathrm{~h}$ treatment (Fig. 1c). In $\mathrm{H} 460$ cells, the $\mathrm{IC}_{50}$ values were $22.49 \pm$ 4.52, $13.15 \pm 1.02$, and $6.80 \pm 0.72 \mu \mathrm{M}$, respectively, after 12, 24, and $48 \mathrm{~h}$ treatment (Fig. 1d). As shown in Fig. 1e, treatment with 5,10 , and $15 \mu \mathrm{M} \mathrm{LZ-101}$ for $24 \mathrm{~h}$ significantly inhibited the surviving of A549, H1299, and H460 cells with A549 cells being the most sensitive to LZ101. Therefore, A549 cell line was chosen for further experiments with 5,10 , and $15 \mu \mathrm{M}$ of LZ-101 treatment for $24 \mathrm{~h}$. To explore the mechanism of LZ-101 inhibiting A549, H1299, and H460 cells survival, cells were also treated with a pan-caspase inhibitor, Q-VD-OPh, during LZ-101 treatment. Survival inhibition of LZ-101 was significantly inhibited in A549, H1299, and H460 cells, when caspase activity was inhibited by Q-VD-OPh (Fig. 1f). This suggests that LZ-101 inhibited the survival of human nonsmall-cell lung cancer cells by triggering apoptosis.

\section{LZ-101 induced mitochondrial apoptosis in A549 cells}

To detect the apoptosis induced by LZ-101 in A549 cells, DAPI staining assay and Annexin-V/PI staining were used with rotenone as positive control. In DAPI staining assay, control cells emitted blue fluorescence with consistent nucleus intensity and showed typical homogeneous distribution of chromatin in nucleus. After LZ-101 treatment, cells presented morphological features of bright apoptotic bodies and nuclear condensation (Fig. 2a arrows). These features appeared more frequently with increasing concentrations of LZ-101. To further confirm the apoptosis induced by LZ-101, Annexin-V/PI staining assay was used. As shown in Fig. 2b, increased apoptotic was detected after LZ-101 treatment for $24 \mathrm{~h}$. The percentage of apoptotic cells increased from $6.07 \% \pm 1.62 \%$ to $14.92 \% \pm 4.32 \%, \quad 22.07 \% \pm 4.32 \%$, and $43.62 \% \pm 7.83 \%$, respectively. Furthermore, the apoptosis related proteins such as Bcl-2, Bax, caspase-9 and PARP were investigated by Western blots. After treatment with LZ-101 for $24 \mathrm{~h}$, the apoptotic protein Bax expression increased while the anti-apoptotic protein $\mathrm{Bcl}-2$ expression decreased in a concentration-dependent manner (Fig. 2c). The ratio of $\mathrm{Bax} / \mathrm{Bcl}-2$ is crucial for the activation of the mitochondrial apoptotic pathway. The ratio of $\mathrm{Bax} / \mathrm{Bcl}-2$ was increased by different concentrations of LZ-101 treatment. Besides, Caspase- 9 and PARP cleavage were activated significantly after LZ-101 treatment (Fig. 2c). These data indicated that LZ-101 induced apoptosis in A549 cells.

In order to elucidate the mechanism of LZ-101-induced apoptosis in A549 cells, we investigated the effect of LZ101 on mitochondrial function. Changes in mitochondrial functions are essential for mitochondrial apoptotic pathway. In early apoptosis stage, the change of mitochondrial membrane potential $(\Delta \Psi m)$ is a marker for mitochondrial dysfunction. Accordingly, we used a fluorogenic probe JC- 
A

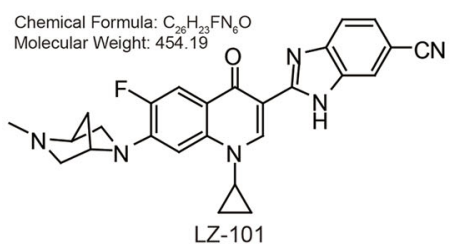

C

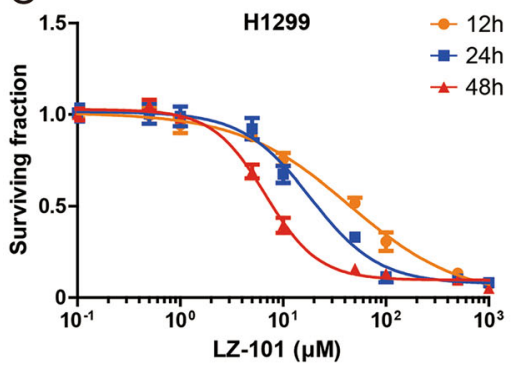

$\mathrm{E}$

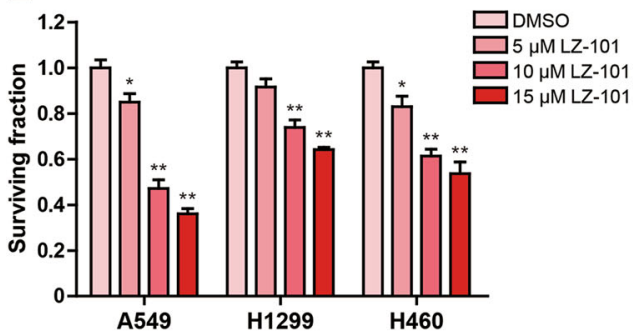

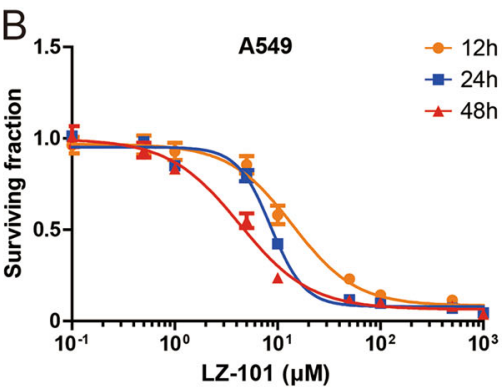

D

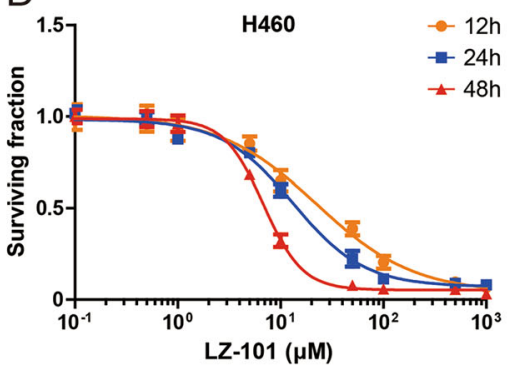

$\mathrm{F}$

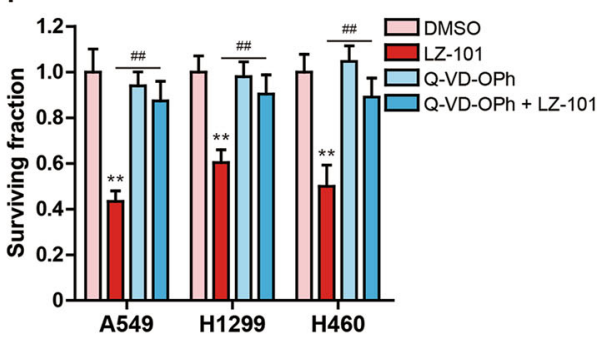

Fig. 1 LZ-101 inhibits the viability of human non-small-cell lung cancer cells. a $\mathrm{LZ}-101$ molecular structure $\left(\mathrm{C}_{26} \mathrm{H}_{23} \mathrm{FN}{ }_{6} \mathrm{O}, \mathrm{Molecular}_{\mathrm{W}} \mathrm{Weight:}\right.$ 454.19). Effect of LZ-101 on the viability of human non-small cell lung cancer cells. MTT assay was used to detect cell viability after treatment of different concentrations of LZ-101 for 12 h, 24 h, and 48 h in A549 (b), H1299 (c) and H460 (d). e Cell viability was detected after treatment of 5, 10, and $15 \mu \mathrm{M}$ LZ-101 for $24 \mathrm{~h}$ in A549, H1299, and H460 cells. f Cell viability was detected after treatment of $20 \mu \mathrm{M}$ Q-VD-OPh or $15 \mu \mathrm{M}$ LZ-101 for $24 \mathrm{~h}$ in A549, H1299, and H460 cells. Data are presented as mean \pm SD. ${ }^{*} P<0.05,{ }^{* *} P<0.01$ compared with DMSO group. ${ }^{\# \#} P<0.01$

1 staining cells to detect the change of $\Delta \Psi m$ after LZ-101 treatment. Flow cytometric analysis revealed that A549 cells became more susceptible to mitochondrial membrane depolarization after LZ-101 treatment (Fig. 2d). We observed almost $50 \%$ decrease in $\Delta \Psi m$ with $15 \mu \mathrm{M}$ LZ101 , compared with the control group. Multidomain proapoptotic proteins like Bax and Bak play pivotal roles in the release of apoptogenic proteins, such as cytochrome $c$ and AIF, from the mitochondria into the cytosol in response to apoptotic stimuli ${ }^{20}$. To study the involvement of Bax in LZ-101-induced apoptosis, we used Bax shRNA to diminish the expression of Bax (Fig. 2e). As shown in Fig. 2f, cytochrome $c$ and AIF were released from mitochondria upon LZ-101 treatment whereas their release was almost completely blocked in Bax knockdown cells and $\beta$-actin levels of all the fractions were similar. Taken together, our findings suggested that LZ-101 induced apoptosis was mediated by mitochondrial dysfunction in A549 cells.

\section{The up-regulation of FOXO3a expression was involved in} LZ-101 induced apoptosis of mitochondrial

When cells receive intrinsic apoptosis signals, the proapoptotic BH3-only proteins, such as Bim, Bad, Noxa, and Puma, will be activated. These proteins not only inhibit the activity of anti-apoptotic protein (Bcl-2, Bcl-xL, and Mcl-1), but also activate the pro-apoptotic protein (Bax and Bak), which form an oligomer and subsequently punch pores in the outer mitochondrial membrane, eventually, leading to permeabilization of mitochondrial outer membrane ${ }^{6}$. As mentioned before, although proapoptotic BH3-only protein Bim plays a crucial role in apoptosis, it could be regulated by FOXO3a at transcriptional level. Therefore, we investigated the effect of 
A
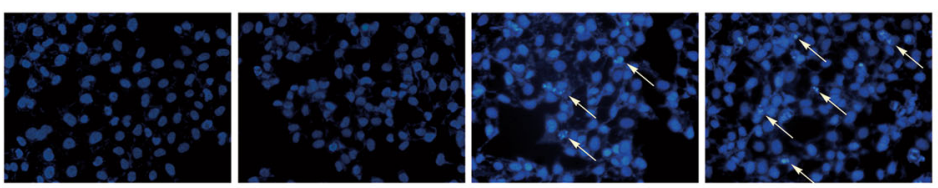

Control

5

10

15

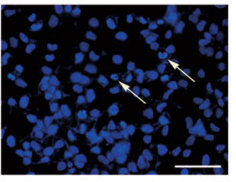

Rotenone

$\mathrm{LZ}-101(\mu \mathrm{M})$

$(5 \mu \mathrm{M})$

B
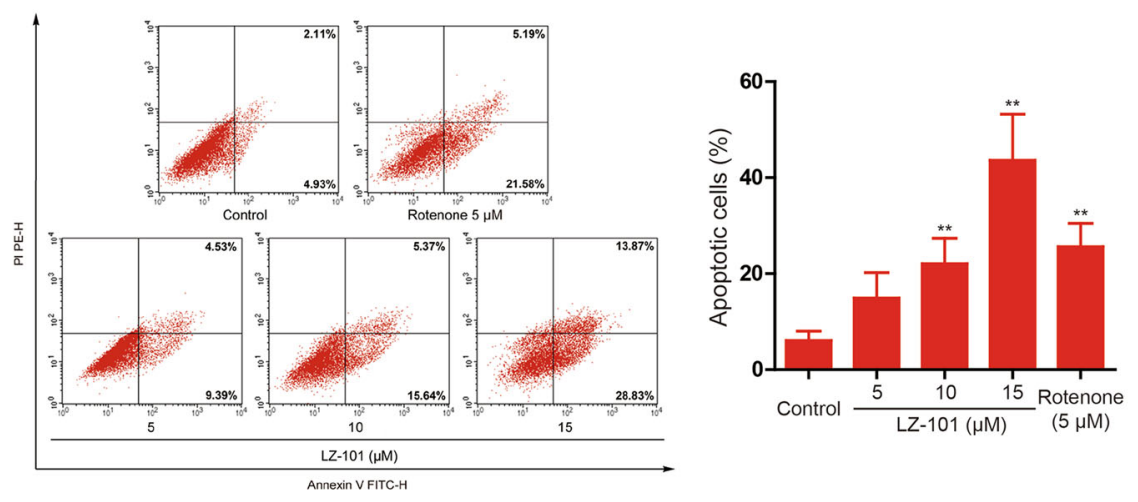

C
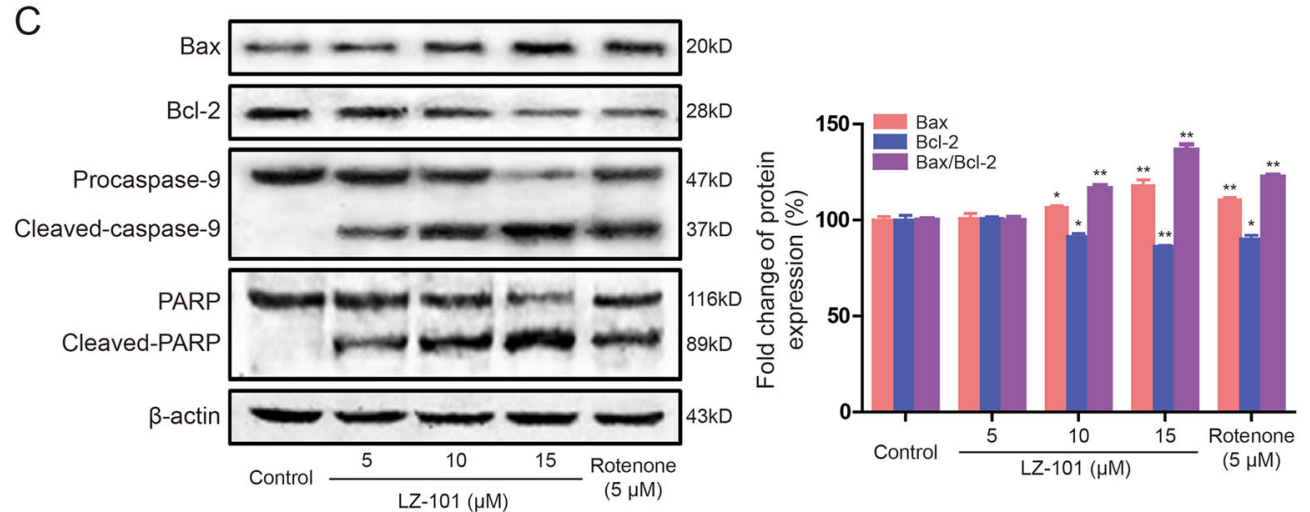

D
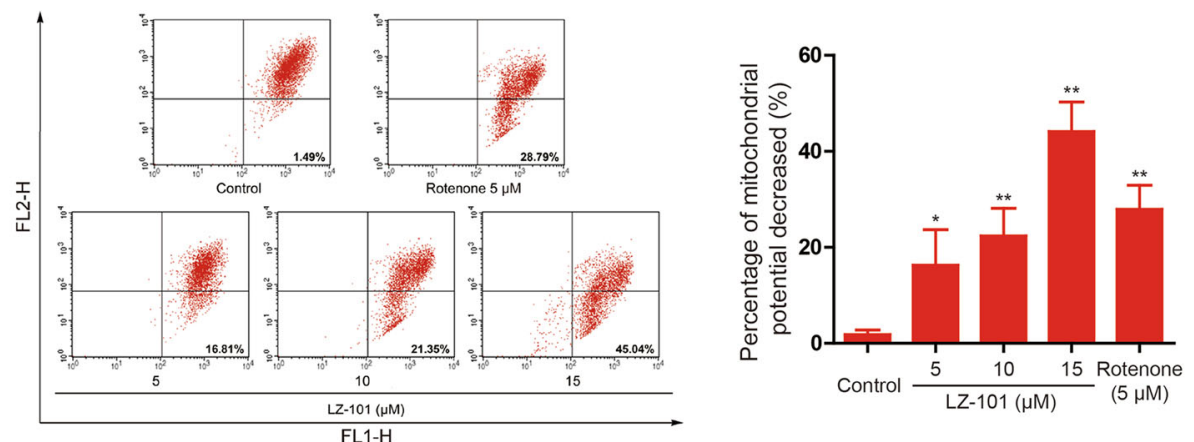

E

$\mathrm{F}$

Cytosolic fraction
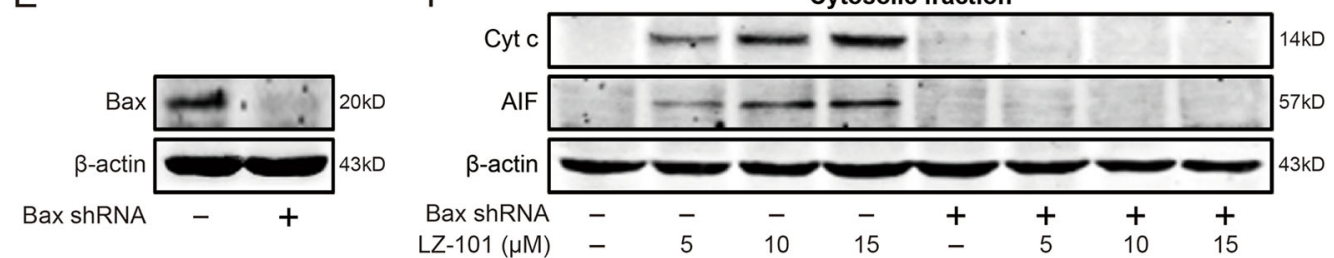

Fig. 2 (See legend on next page.) 
(see figure on previous page)

Fig. 2 LZ-101 induces mitochondrial apoptosis in A549 cells. A549 cells were exposed to LZ-101 (5, 10, and $15 \mu \mathrm{M})$ or Rotenone (5 $\mu \mathrm{M})$ for $24 \mathrm{~h}$. a DAPI staining was used to detect the apoptosis. Scale bars, $50 \mu \mathrm{m}$. b Induction of apoptosis were measured by Annexin-V/PI double-staining assay (left). Histograms shows the distribution of apoptotic cells for three independent experiments (mean \pm SD) (right). c The levels of Bax, Bcl-2, caspase-9, and PARP were assessed by western blot. Ratio of Bax/Bcl-2 expression using densitometric analysis. $\mathbf{d}$ The change of $\Delta \psi_{m}$ as detected by flow cytometry using JC-1 staining. e Bax were detected by western blot after transfection of Bax shRNA into A549 cells. f The release of Cyt $c$ and AIF from mitochondria into cytoplasm was measured by Western blot assay. Data are presented as mean \pm SD. ${ }^{*} P<0.05,{ }^{* *} P<0.01$ compared with DMSO group

LZ-101 on this signaling pathway. Western blots analysis showed that Bim increased in A549 cells after LZ-101 treatment for $24 \mathrm{~h}$ (Fig. 3a). This result confirms that FOXO3a regulated the transcription of Bim. Moreover, we found that LZ-101 up-regulated FOXO3a protein expression in A549 cells (Fig. 3a). The change of mRNA level of Bim, tested by Real-time PCR, was consistent with that of the protein levels (Fig. 3b). Furthermore, Luciferase reporter gene assay suggested that LZ-101 increased transcriptional activity of FOXO3a in a concentrationdependent manner (Fig. 3c). LZ-101 also promoted FOXO3a to translocate into the nucleus (Fig. 3d). Therefore, LZ-101 up-regulates the expression of FOXO3a and promotes the transcription of Bim.

To further explore the mechanism of LZ-101-induced apoptosis and determine the roles of FOXO3a activation in this process, we detected the influence of LZ-101 on Bax and Bcl-2 expression after FOXO3a siRNA transfection. Western blot results showed that the protein level of $\mathrm{Bax}$ and $\mathrm{Bcl}-2$ were notably regulated by LZ-101. However, these effects of LZ-101 were obviously reversed by the knockdown of FOXO3a (Fig. 3e). Remarkably, the ratio of Bax/Bcl-2 increased by LZ-101 was also reversed. Moreover, Flow cytometry analysis demonstrated that the percentage of apoptotic cells in LZ-101 group transfected with FOXO3a siRNA reduced from $50.47 \% \pm 8.59 \%$ to $19.44 \% \pm 3.63 \%$, compared with LZ-101 group without transfection with FOXO3a siRNA (Fig. 3f). The decrease of mitochondrial potential was inhibited in LZ-101 group transfected with FOXO3a siRNA compared with LZ-101 group (Fig. 3g). In conclusion, the up-regulation of FOXO3a expression was involved in the induction of mitochondrial apoptosis by LZ-101.

\section{LZ-101 increased the stability of FOXO3a in a proteasome- independent manner}

To further investigate the molecular mechanism by which LZ-101 up-regulates FOXO3a expression, de novo protein synthesis inhibitor cycloheximide (CHX) and proteasome inhibitor MG132 were used, respectively. After treatment of CHX, FOXO3a was more stable in A549 cells treated by LZ-101 compared with A549 cells treated by DMSO (Fig. 4a), indicating that LZ-101 interfered with FOXO3a degradation. In support of this observation, when MG132 $(20 \mu \mathrm{M})$ was added to A549 cells, increased FOXO3a levels were observed, whereas LZ-101 unexpectedly further increased FOXO3a levels in A549 cells treated with MG132 (Fig. 4b). Further detection of apoptosis levels showed that LZ-101 significantly increased apoptosis induced by MG132 (Fig. 4c). These results suggested that LZ-101 interfered with FOXO3a degradation in a proteasome-independent manner. In addition to proteasome degradation of proteins in cells, the autophagic lysosomal pathway may also be involved in protein degradation. To confirm this hypothesis we detected the co-localization of FOXO3a and LAMP1 in A549 cells. As shown in Fig. 4d, LZ-101 indeed inhibited the co-localization of FOXO3a and LAMP1. To further confirm FOXO3a is degraded by the autophagic lysosomal pathway, an autophagolysosome inhibitor, bafilomycin A1, was used. After treatment with bafilomycin A1, FOXO3a degradation was inhibited, combination of bafilomycin A1 with LZ-101 could not further inhibit FOXO3a degradation (Fig. 4e). These results suggested that LZ-101 increased the stability of FOXO3a through the autophagic lysosome pathway rather than the ubiquitin proteasome pathway.

\section{LZ-101 blocked autophagy flux in A549 cells}

In Fig. 4d, $100 \mathrm{nM}$ rapamycin remarkably increased the co-localization of FOXO3a and LAMP1 in A549 cellls. This is consistent with the study that FOXO3a is an autophagy substrate ${ }^{16}$. To further investigate the molecular mechanism by which LZ-101 increased the stability of FOXO3a, we investigated the effect of LZ-101 on autophagy. LC3-I and LC3-II are both produced posttranslationally, but LC3-I is cytosolic and LC3-II, the hallmarks of autophagy, is membrane bound and forms the autophagosome ${ }^{21}$. Treatment with $15 \mu \mathrm{M}$ LZ-101 increased GFP-LC3 puncta accumulation (Fig. 5a). Then, we assessed LC3 in the cell lysates by immunoblot analysis. We found that LC-II protein levels gradually increased following treatment with LZ-101 in A549 cells (Fig. 5b), indicateing that LZ-101 increased autophagosome formation in A549 cells. Since enhanced autophagosome accumulation could be caused either by promoted autophagosome formation or by suppressed autophagosome degradation, we determined whether a 


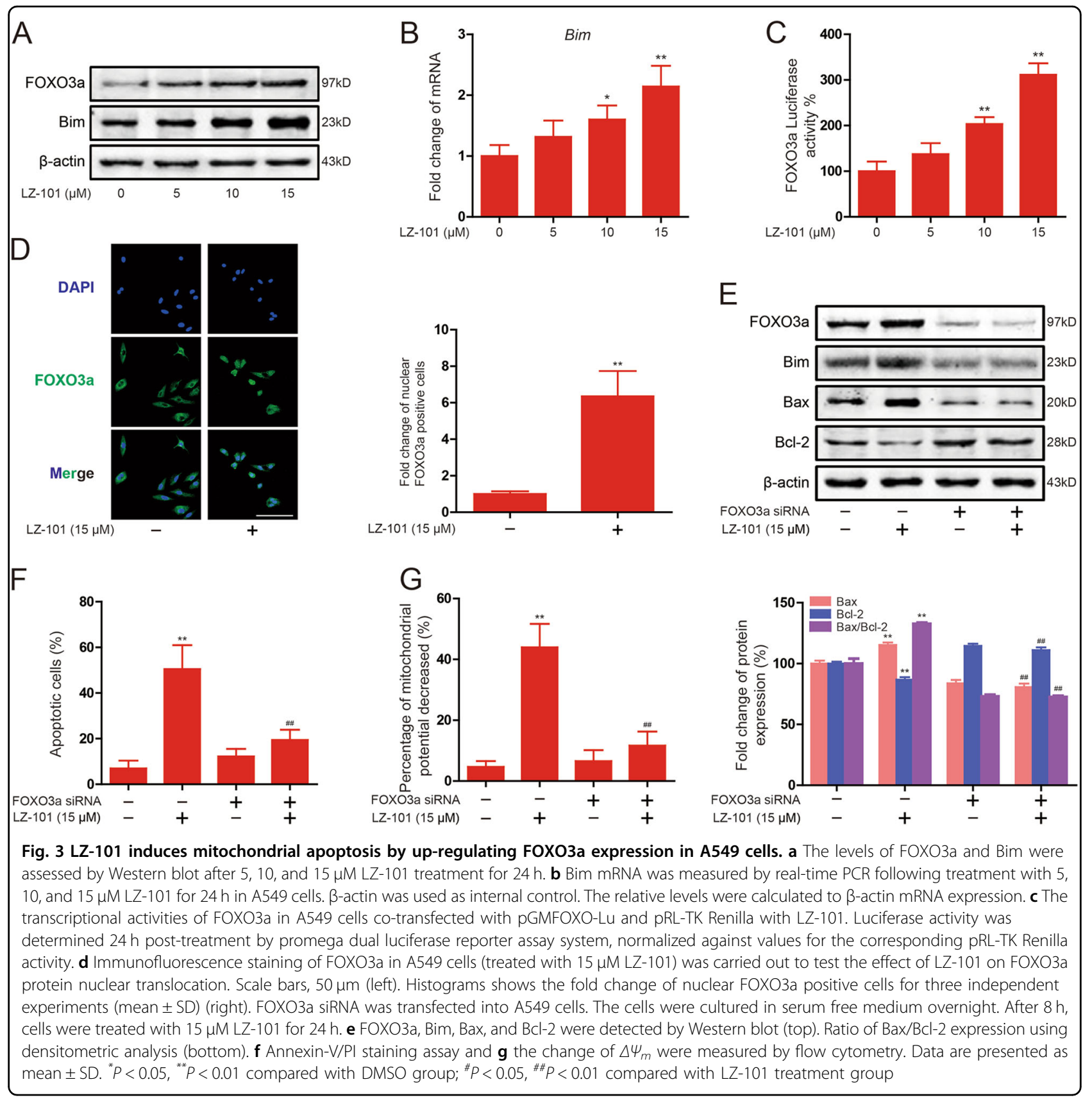

complete autophagic flux occurred after LZ-101 treatment. As shown in Fig. 4b, the degradation of p62 was significantly suppressed in A549 cells with LZ-101 treatment. To further assess the status of autophagic flux, we used the mCherry-GFP-LC3 construct. As the more stable of mCherry in acidic conditions compared with GFP, autophagic flux can be determined by the appearance of more $\mathrm{GFP}^{-} \mathrm{mCherry}^{+}$(red) puncta. After treatment with LZ-101, large-sized $\mathrm{GFP}^{+} \mathrm{mCherry}^{+}$(yellow) puncta were observed, while the yellow puncta did not change significantly after bafilomycin A1 treatment (Fig. 5c, d).
These results indicated that LZ-101 blocked autophagy flux in A549 cells by inhibiting autophagosome degradation.

\section{Inhibition of autophagosome formation abolished the induction of apoptosis by LZ-101}

To investigate the role of autophagy in the induction of apoptosis by LZ-101, we blocked the formation of autophagosomes with 3-MA. After treatment with 3-MA, the effect of LZ-101 to stabilize FOXO3a abolished (Fig. 6a). In addition, the effect of LZ-101 induced apoptosis 

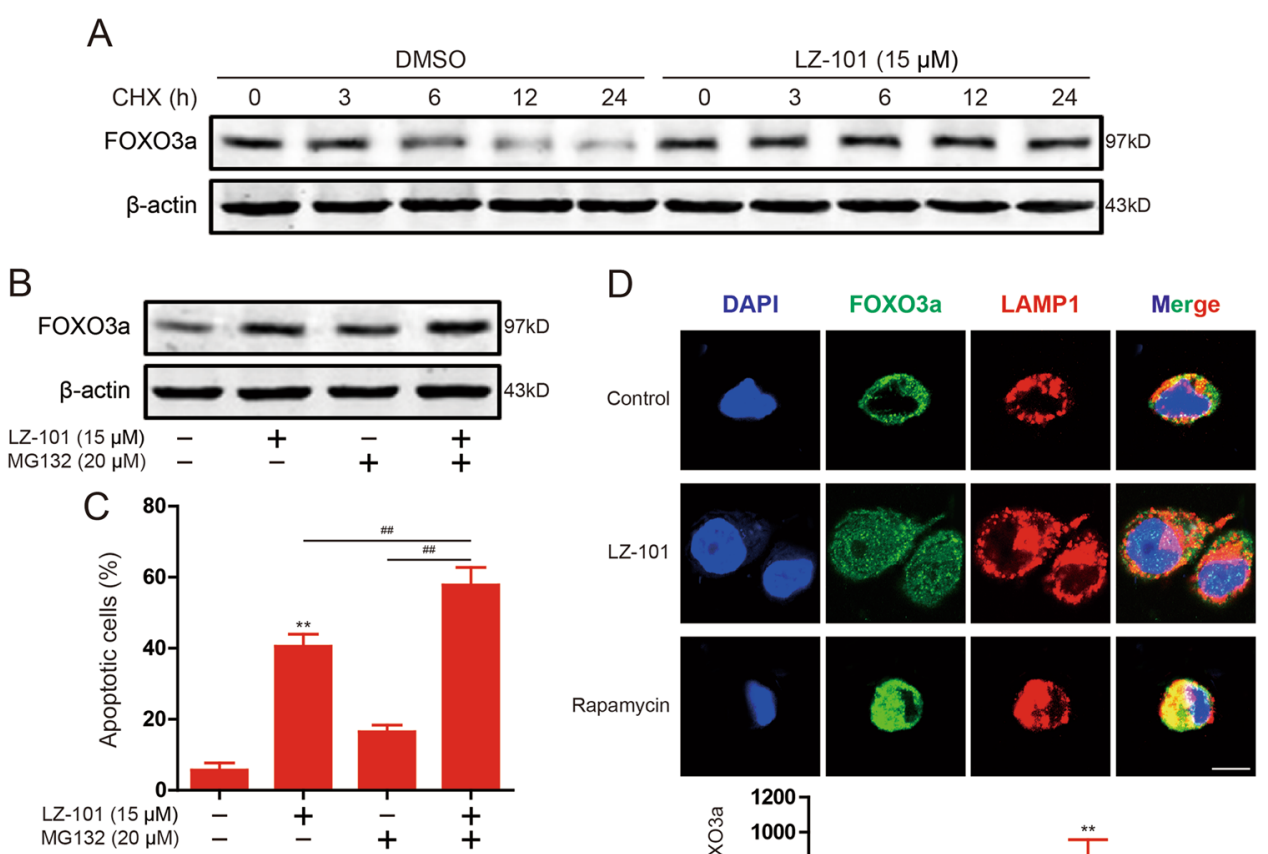

MG132 $(20 \mu \mathrm{M})$

E
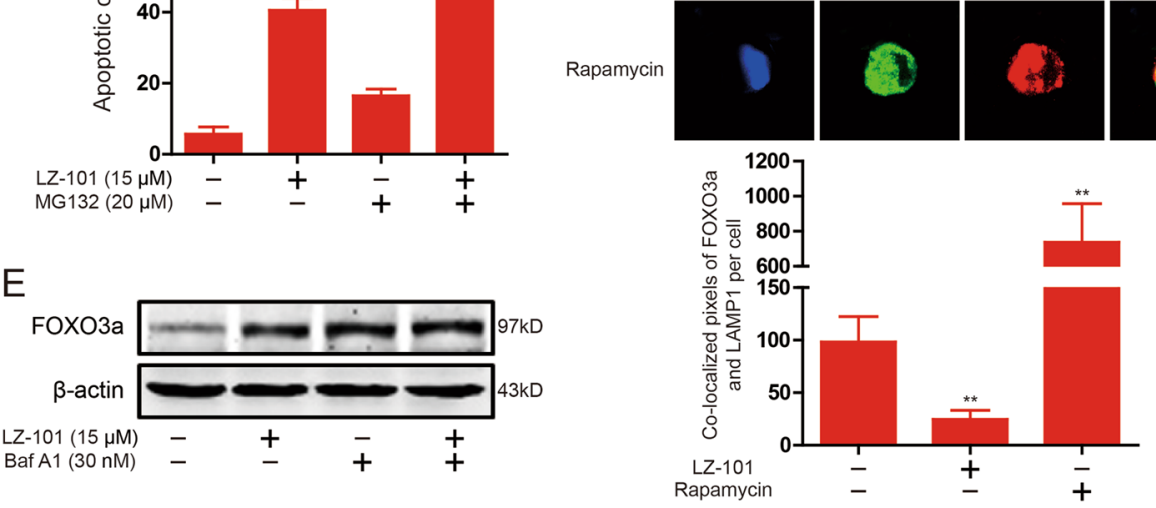

Fig. 4 LZ-101 stabilized FOXO3a proteins in a proteasome-independent manner in A549 cells. a Degradation dynamics of FOXO3a following a time course CHX treatment in A549 cells treated with $15 \mu \mathrm{M}$ LZ-101. b FOXO3a proteins were stabilized in the presence of MG132 (20 $\mu$ M) in A549 cells treated with $15 \mu \mathrm{M}$ LZ-101. c Annexin-V/PI staining assay measured by flow cytometry in the presence of MG132 (20 $\mu$ M) in A549 cells treated with $15 \mu \mathrm{M}$ LZ-101. d Confocal microscopy of A549 cells treated with $15 \mu \mathrm{M}$ LZ-101 or $100 \mathrm{nM}$ rapamycin, immunostained for FOXO3a (green) and LAMP-1 (red). Scale bars, $10 \mu \mathrm{m}$ (top). Histograms shows the co-localized pixels of FOXO3a and LAMP1 per cell for three independent experiments (mean \pm SD) (bottom). e FOXO3a was detected by Western blot after $15 \mu \mathrm{M}$ LZ-101 and $30 \mathrm{nM}$ bafilomycin A1 treatment. Data are presented as mean \pm SD. ${ }^{*} P<0.05,{ }^{* *} P<0.01$ compared with DMSO group; ${ }^{\#} P<0.05,{ }^{\#} P<0.01$

was similarly abolished after treatment with 3-MA (Fig. 6b). In the process of autophagy, ATG5 and ATG7 are required for the formation of the autophagosome ${ }^{22}$. As shown in Fig. 6c, we silenced the expression of ATG5 or ATG7 through transfecting siRNA. The induction of apoptosis was abolished after diminishing the expression of ATG5 or ATG7 in LZ-101-treated A549 cells (Fig. 6d). Thus, blocking the formation of autophagosome abolished LZ-101 induced apoptosis of A549 cells.

\section{LZ-101 exerted anti-tumor effect with low toxicity in A549 inoculated xenograft mice}

The xenograft mice transplanted with A549 cells were used to evaluate the anti-tumor effect of LZ-101 in vivo. The tumor volume of mice with LZ-101 treatment was smaller than that of mice in control group but larger than that of mice in 5-fluorouracil-treated group at the same measurement day (Fig. 7a). Moreover, the tumor weight of LZ-101-treated mice was significantly smaller than that of the control group (Fig. 7b). Accordingly, the inhibitory rates of 5 -fluorouracil, $10 \mathrm{mg} / \mathrm{kg}$ and $20 \mathrm{mg} / \mathrm{kg} \mathrm{LZ-101}$ groups were $68.05 \%, 40.86 \%$, and $55.62 \%$, respectively (Table 1). The TUNEL assay was performed to detect apoptotic cells in tumor tissues. The results indicated that DNA damage in tumor tissues was induced by LZ-101. In addition, immunohistochemical analysis showed that Bcl2 expression were decreased while FOXO3a, Bim and Bax expression were increased after LZ-101 treatment (Fig. 7c). Furthermore, we monitored the toxicity of LZ101 during the entire in vivo experiment. LZ-101 treatment (21 days) did not cause any physical abnormalities. Hematological parameters showed that there were no notable changes in the analyzed parameters in the experimental animals, as listed in Table 2 with the standard ranges for mice. Besides, there was no significant difference in the average body weight of LZ-101-treated 

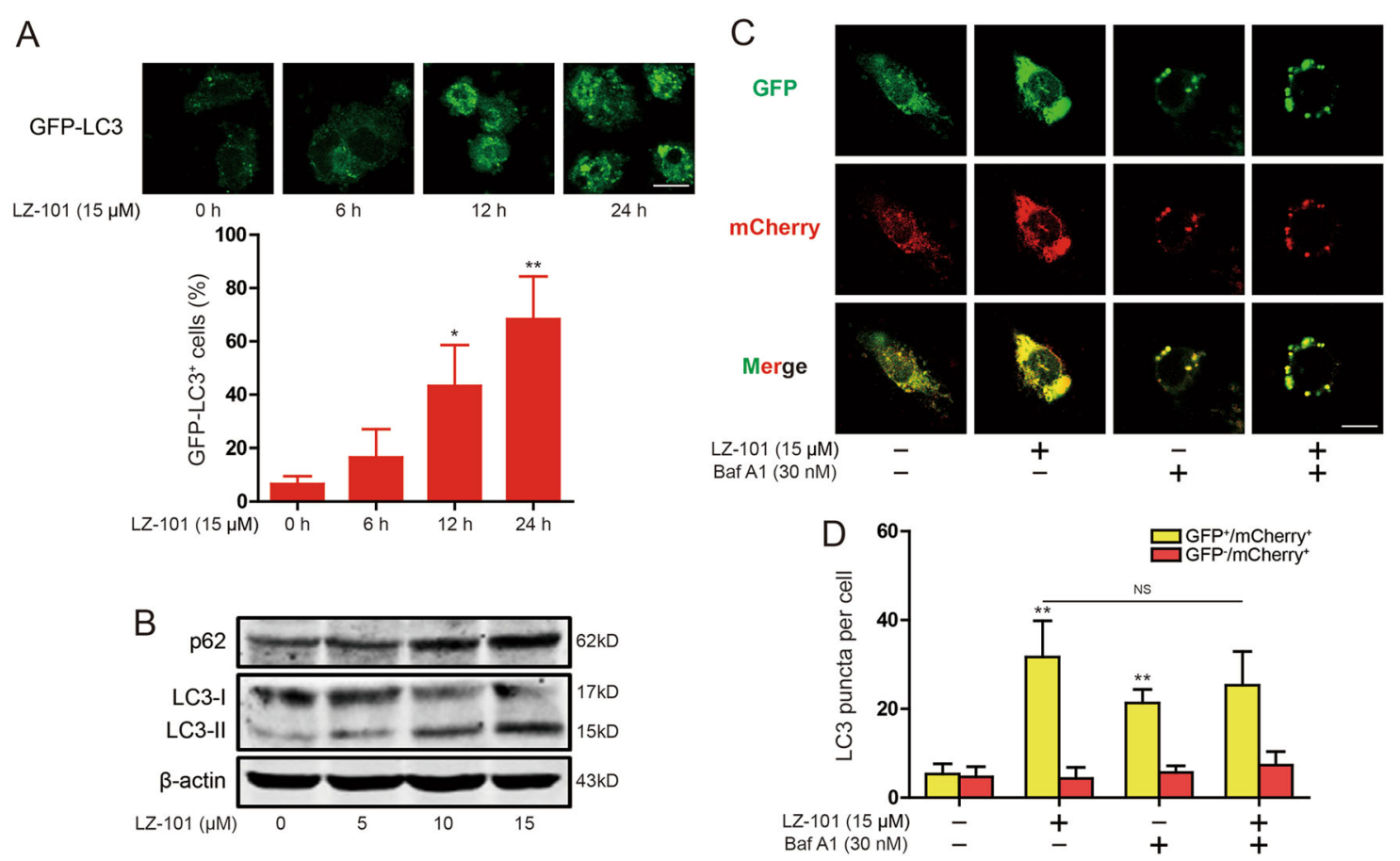

Fig. 5 LZ-101 blocked autophagy flux in A549 cells. a Induction of GFP ${ }^{+}$dots in A549 cells expressing GFP-LC3 treated with 15 $\mu M$ LZ-101. Images of individual cells and quantified of GFP-LC3 ${ }^{+}$cells. Scale bars, $10 \mu \mathrm{m}$. b p62 and LC3 were detected by western blot in A549 cells treated with $15 \mu \mathrm{M}$ LZ-101. c A549 cells expressing mCherry-GFP-LC3 were observed under a confocal microscopy after $15 \mu \mathrm{M}$ LZ-101 and $30 \mathrm{nM}$ bafilomycin A1 treatment. Representative images are shown. Scale bars, $10 \mu \mathrm{m}$. $\mathbf{d}$ The average numbers of yellow or red puncta were obtained from three countings. Data are presented as mean $\pm \mathrm{SD} .{ }^{*} P<0.05,{ }^{* *} P<0.01$ compared with DMSO group

mice compared with that of the control mice (Fig. 7d). H\&E staining (Fig. 7e) showed no morphological changes in the organs of mice with LZ-101 treatment. Taken together, our results suggested that LZ-101 inhibited tumor growth via FOXO3a activation in xenograft mice bearing A549 tumor with low toxicity in vivo.

\section{Discussion}

LZ-101 is a derivative of danofloxacin, a fluoroquinolone antibiotic used in veterinary medicine. Previous studies indicated that high concentrations of danofloxacin displayed cytotoxic effects involved apoptosis and/or necrosis. Danofloxacin also induced a concentration-dependent increase in ROS production in renal tubular cells epithelial cell line (LLC-PK1) ${ }^{23}$. In the current study, we showed that LZ-101 had an effective anti-tumor activity in vitro and in vivo by stabilizing FOXO3a via blocking autophagy flux, eventually leading to mitochondrial-mediated apoptosis.

Primarily, we found that LZ-101 could induce apoptosis (Fig. 2a-c) and trigger caspase-9 activation and PARP cleavage in A549 cells. Moreover, LZ-101 increased the ratio of $\mathrm{Bax} / \mathrm{Bcl}-2$, the mitochondrial apoptotic indicator. These results suggested that LZ-101 induced apoptosis probably by activation of the mitochondrial apoptotic pathway. Therefore, we further investigated the effect of LZ-101 on mitochondrial apoptosis. The mitochondrial apoptotic pathway is comprised of a series of continuous processes. Our results showed that LZ-101 treatment remarkably decreased mitochondrial membrane potential, a marker for mitochondrial dysfunction in early apoptosis stage. During apoptosis, cytochrome $c$ and AIF retained within mitochondria, are released from the intermembrane space into the cytosol. Afterwards, cytosolic cytochrome $c$ binds to Apaf-1 to form the apoptosome which subsequently recruit procaspase- 9 and facilitate its activation. Ultimately, caspase- 9 efficiently cleaves and activates downstream caspase-3, leading to apoptosis ${ }^{24}$. AIF translocates from the mitochondria to the nucleus and causes chromatin condensation and DNA fragmentation $^{25}$. Our results suggested that LZ-101 induced the release of cytochrome $c$ and AIF from mitochondria into the cytosol, which was dependent on Bax expression (Fig. 2e, f). Taken together, our study implied that LZ-101 induced apoptosis via mitochondrial apoptotic pathway.

The Bcl-2 family proteins are most important regulators for apoptosis. This family consists of three subfamilies: anti-apoptotic members, pro-apoptotic members, and BH3-only members. Therein, the BH3-only members are normally triggered to mitochondrial translocation in 

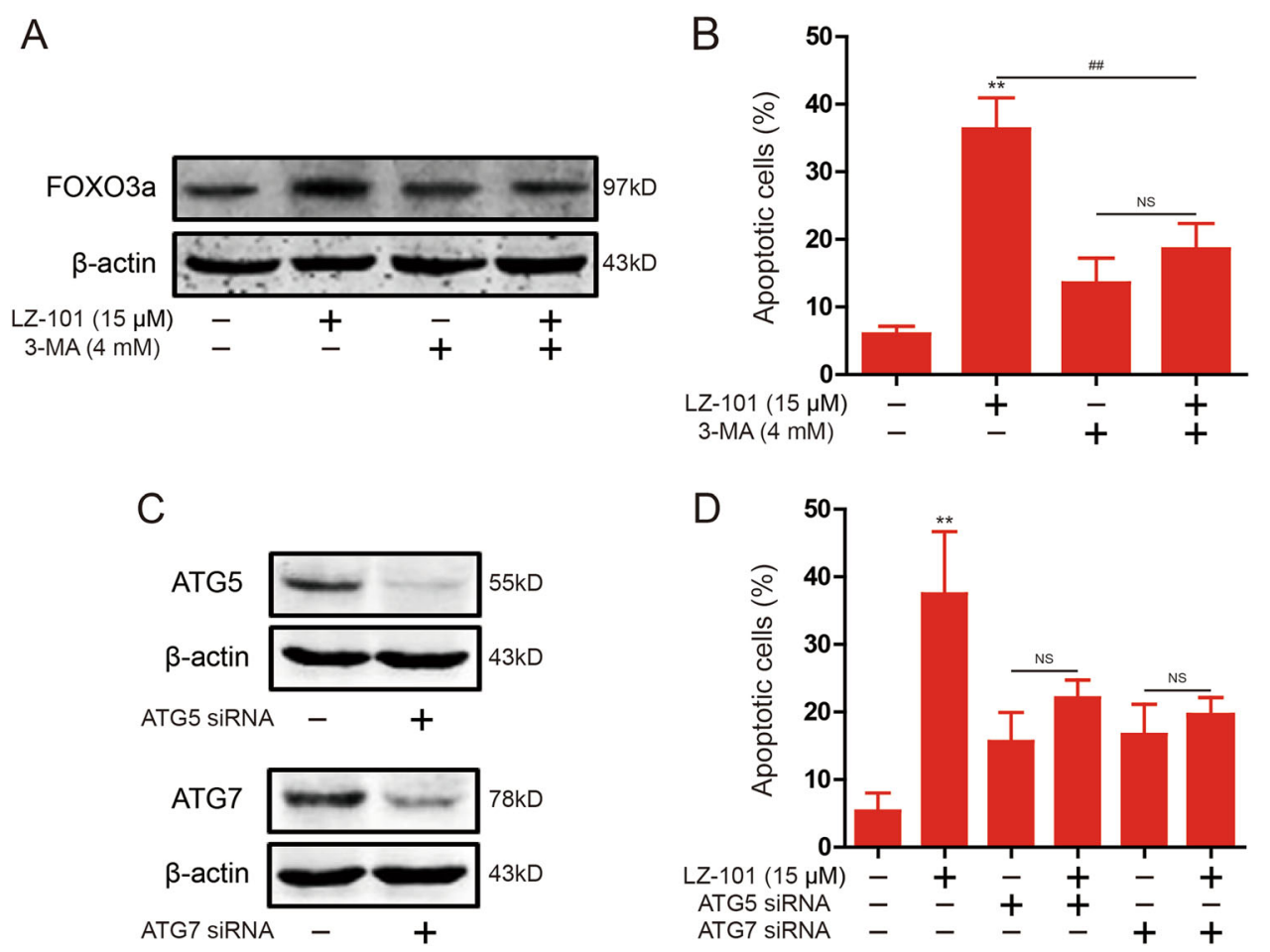

Fig. 6 Apoptosis induced by LZ-101 was abolished after inhibition of autophagosome formation in A549 cells. a FOXO3a was detected by western blot in the presence of 3-MA (4 mM) in A549 cells treated $15 \mu \mathrm{M} \mathrm{LZ-101.} \mathbf{b}$ Annexin-V/PI staining assay by flow cytometry in the presence of 3-MA (4 mM) in A549 cells treated with $15 \mu \mathrm{M}$ LZ-101. c ATG5 and ATG7 were detected by western blot after transfection of ATG5 or ATG7 siRNA into A549 cells. d Annexin-V/PI staining assay by flow cytometry in A549 cells treated with $15 \mu \mathrm{M}$ LZ-101 and transfected ATG5 or ATG7 siRNA. Data are presented as mean $\pm \mathrm{SD} .{ }^{*} P<0.05,{ }^{* *} P<0.01$ compared with DMSO group

response to apoptotic stimuli ${ }^{26}$. Once translocated into the mitochondria, they cause mitochondrial dysfunction and release pro-apoptotic proteins by interacting with other members of the $\mathrm{Bcl}-2$ family ${ }^{27}$. Bim is a member of BH3-only proteins that bind to dynein light chain LC8 of microtubule complexes ${ }^{28}$. During apoptosis, Bim disassociates from the microtubule complex and translocates to the mitochondria, leading to the release of cytochrome c. When Bim gets into the mitochondria, the proapoptotic members of the Bcl-2 family, such as Bax and Bak, oligomerize into mitochondrial pores that are required to induce the release of pro-apoptotic proteins ${ }^{29}$. The members of the anti-apoptotic family, such as Bcl-2 and Bcl-xL, block the oligomerization of Bax and Bak but do not affect the translocation of the $\mathrm{BH} 3$-only proteins to the mitochondria ${ }^{30-32}$. In our study, LZ-101 promoted Bax and Bim expression and inhibited Bcl-2 expression (Figs. 2c and 3a). Transcriptional regulation of Bim may be important for apoptosis. It has been documented that Forkhead transcription factor FOXO3a, the most important transcription factor in FOXO family, induced Bim transcription $^{33}$. Our study demonstrated that LZ-101 promoted FOXO3a expression, nuclear translocation and transcriptional activity. Further studies showed that LZ-
101 inhibited FOXO3a degradation is independent of the proteasome pathway (Fig. 4a-c). Since the ubiquitin proteasome system and the autophagic lysosomal system are involved in the degradation of FOXO3a, we next studied the effect of LZ-101 on the autophagic lysosomal pathway. As shown in Fig. 4d, LZ-101 inhibited the colocalization of FOXO3a and LAMP-1. The combination of bafilomycin A1 and LZ-101 failed to further inhibit the degradation of FOXO3a (Fig. 4e). Further investigation of the effect of LZ-101 on autophagy revealed that LZ-101 could increase the accumulation of autophagosomes and block the autophagy flux (Fig. 5). Moreover, pharmacological or genetic inhibition of autophagosomes formation abolished FOXO3a stabilization and apoptosis induced by LZ-101 (Fig. 6). These results indicated that LZ-101 induced apoptosis by blocking autophagy-dependent FOXO3a degradation. Consistent with our in vitro studies, LZ-101 significantly suppressed the tumor growth of A549 inoculated xenograft mice with low toxicity in major organs. Mechanistically, we found that LZ-101 could induce apoptosis and regulate the expression of relevant proteins in tumor tissues (Fig. 7).

In summary, LZ-101 displayed strong anti-tumor activity both in vitro and in vivo based on the 

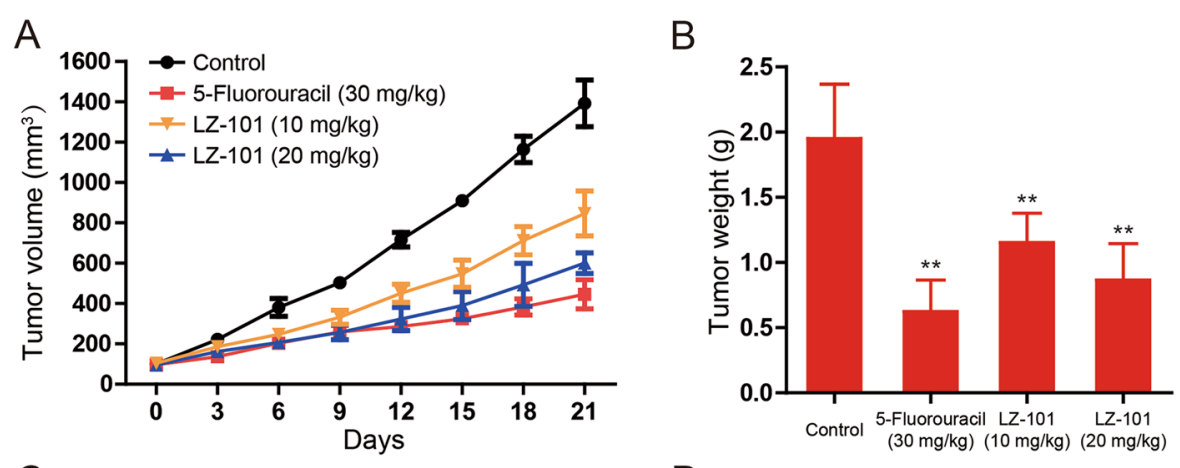

C

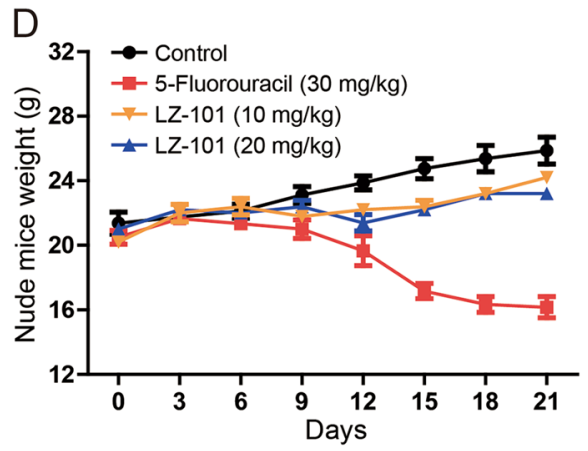

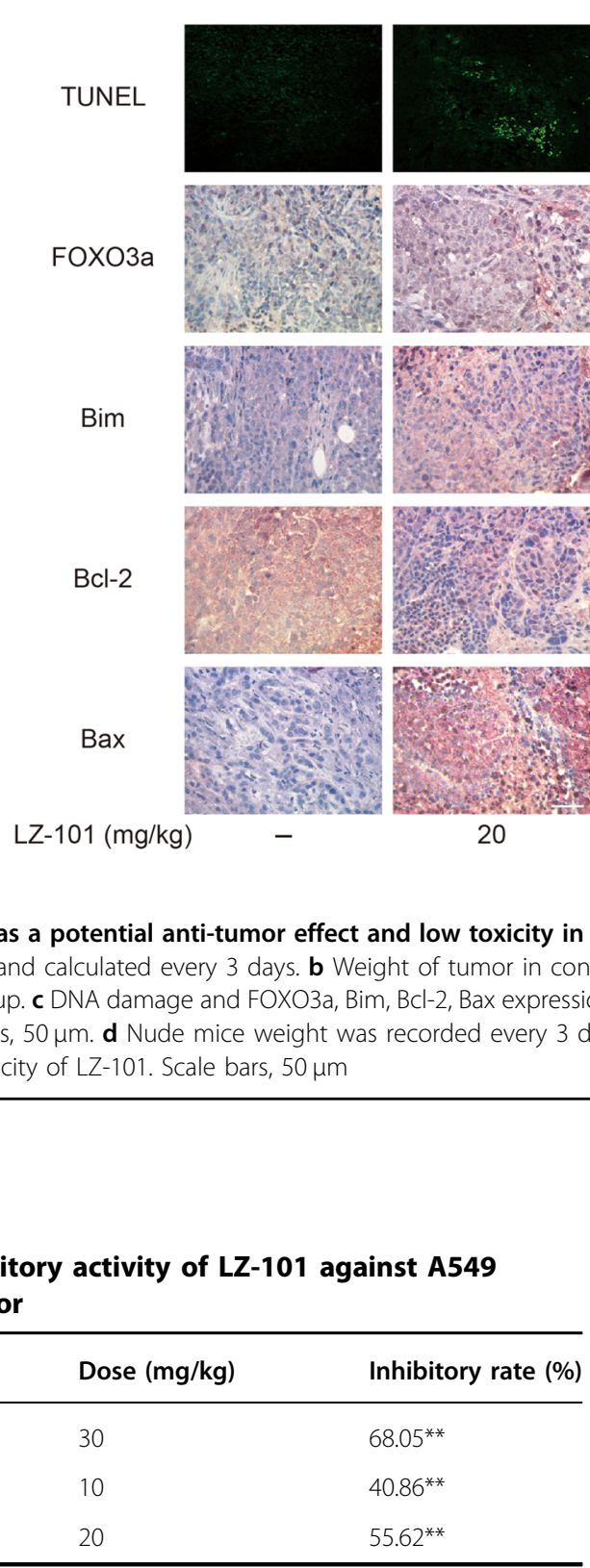

Table 1 Inhibitory activity of LZ-101 against A549 xenograft tumor

\begin{tabular}{lll}
\hline Groups & Dose $(\mathbf{m g} / \mathbf{k g})$ & Inhibitory rate (\%) \\
\hline 5-Fluorouracil & 30 & $68.05^{* *}$ \\
LZ-101 & 10 & $40.86^{* *}$ \\
& 20 & $55.62^{* *}$ \\
\hline
\end{tabular}

Each data point represents the mean SD of six mice ${ }^{* *} P<0.01$ versus control group mitochondrial apoptosis induced by up-regulation of Bim through stabilizing FOXO3a in autophagic lysosomaldependent manner (Fig. 8). However, how FOXO3a escapes from autophagosomes to induce transcription remains unknown. Studies have shown that inhibition of autophagy in different means promoted the transcription of FOXO3a ${ }^{16}$. It was suggested that inhibition of autophagy induced FOXO3a activation was not a specific function of LZ-101. Therefore, the relationship between autophagy and FOXO3a activation needs further study and is underway in our laboratories. In conclusion, this 
study indicated that LZ-101 could be a potential effective agent with low toxicity for human non-small-cell lung carcinoma.

Table 2 Hematology profile in non-tumor bearing athymic nude mice administered with normal saline. Two mice per group were used. Standard ranges were obtained in house from 100 normal BALB/c mice of 8-12 weeks age

\begin{tabular}{lllll}
\hline $\begin{array}{l}\text { Hematological } \\
\text { parameters }\end{array}$ & Control & $\mathbf{1 0} \mathbf{~} \mathbf{g} / \mathbf{k g}$ & $\mathbf{2 0} \mathbf{~ m g} / \mathbf{k g}$ & Standard \\
\hline $\begin{array}{l}\text { White blood cells } \\
\left(\times 10^{3} \mu \mathrm{l}\right)\end{array}$ & $4.71 / 4.42$ & $4.90 / 4.95$ & $5.87 / 5.74$ & $4.5-9.1$ \\
$\begin{array}{l}\text { Red blood cells } \\
\left(\times 10^{6} / \mu l\right)\end{array}$ & $9.76 / 10.70$ & $10.51 / 9.84$ & $10.25 / 9.30$ & $7.51-16.1$ \\
Hemoglobin (g/dL) & $14.5 / 13.0$ & $15.2 / 14.2$ & $14.9 / 13.9$ & $12.8-16.1$ \\
Hematocrit (\%) & $44.8 / 41.8$ & $47.9 / 45.3$ & $46.9 / 44.7$ & $34-50$ \\
Lymphocytes (\%) & $67.2 / 78.8$ & $50.4 / 61.4$ & $55.4 / 63.1$ & $49-82$ \\
Monocytes (\%) & $2.64 / 4.24$ & $4.54 / 5.24$ & $3.14 / 4.64$ & $2-8$ \\
Eosinophils (\%) & $0.24 / 0.34$ & $0.04 / 0.74$ & $0.54 / 0.64$ & $0-3$ \\
Basophils (\%) & $0.24 / 0.74$ & $0.34 / 0.34$ & $0.54 / 0.24$ & $0-3$ \\
Platelet (×10 $\left.{ }^{3} \mu l\right)$ & $507 / 410$ & $560 / 483$ & $526 / 744$ & $115-1037$ \\
Mean corpuscular & $45.9 / 45.8$ & $45.6 / 46.0$ & $45.8 / 48.1$ & $41-60$ \\
volume (fL) & & & & \\
Mean corpuscular & $14.9 / 14.3$ & $14.5 / 14.4$ & $14.5 / 14.9$ & $13-19$ \\
hemoglobin (pg) & & & & \\
\hline
\end{tabular}

\section{Materials and methods}

\section{Reagents}

LZ-101 was dissolved in DMSO to make a 100-mM stock and stored at $-20{ }^{\circ} \mathrm{C}$ until needed. The final concentration of DMSO did not exceed $0.1 \%$ throughout the study. 3-(4, 5-dimethylthiazol-2-yl)-2, 5-diphenyltetrazolium bromide (MTT), cycloheximide, 3-MA and diamidino-phenyl-indole (DAPI) were from Sigma (St. Louis, USA). Rapamycin was purchased form Cell Signaling Technology (Danvers, USA). Bovine serum albumin (BSA) was purchased from Roche (Mannheim, Germany).

\section{Antibodies}

Antibodies to Bax, Bcl-2, caspase-9, Cyt $c$, LAMP-1, $\beta$-actin were from Santa Cruz Biotechnology (Dallas, USA). Antibodies to FOXO3a was from Bioworld (St Louis, USA). Antibodies to PARP, COX IV, AIF, Bim, LC3, ATG5, ATG7 were from Cell Signaling Technology (Danvers, USA) and antibody to SQSTM1/p62 were obtained from Abcam (Cambridge, UK). IRDye ${ }^{\mathrm{TM}} 800$ conjugated secondary antibodies were from Rockland Inc. (Philadelphia, USA) and diluted to the ratio of 1:15,000.

\section{Cell culture}

Human non-small cell lung cancer cell line H460 and H1299 cells were cultured in RPMI-1640 medium (Gibco, Waltham, USA) and A549 cells were cultured in F-12 medium (Gibco, Waltham, USA) supplemented with $10 \%$ fetal bovine serum (Gibco, Waltham, USA), $100 \mathrm{U} / \mathrm{ml}$ penicillin and $100 \mathrm{U} / \mathrm{ml}$ streptomycin, cells were cultured

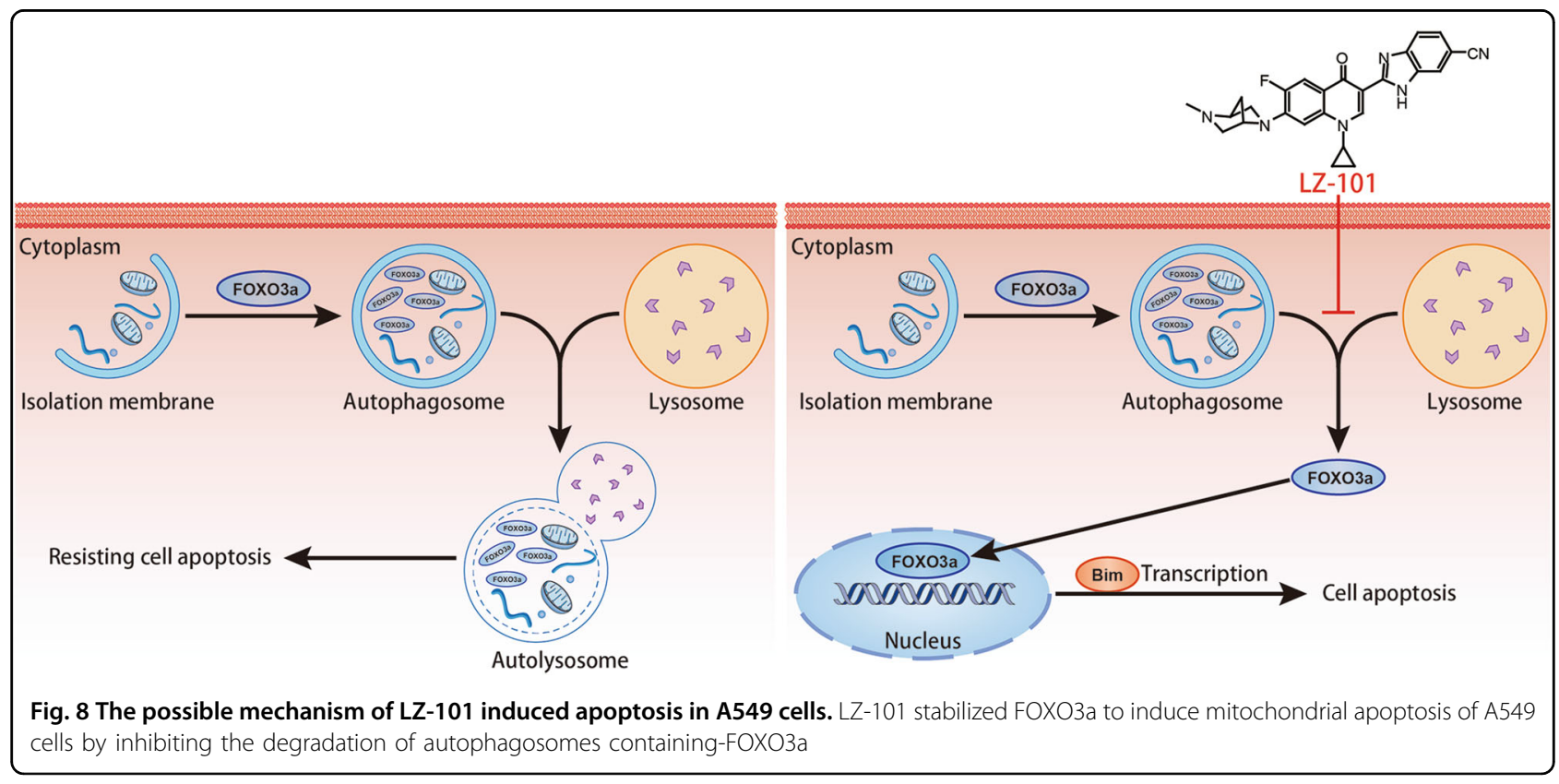


in a humidified $\mathrm{CO}_{2}(5 \%)$ incubator (Thermo Forma, Waltham, USA) at $37^{\circ} \mathrm{C}$.

\section{MTT assay}

Experiments were done in triplicate in a parallel manner for each concentration of LZ-101 used and the results are presented as mean \pm SEM. Control cells were given culture media containing $0.1 \%$ DMSO. After incubation for 24 or $48 \mathrm{~h}, 20 \mu \mathrm{L}$ of $5 \mathrm{mg} / \mathrm{mL}$ MTT was added to cells, and cells were incubated at $37^{\circ} \mathrm{C}$ for another $4 \mathrm{~h}$. The absorbance (A) was measured at $570 \mathrm{~nm}$ using an ELx800 automated microplate reader (BioTek Instruments, Inc.). The inhibitory ratio (\%) was calculated using the following equation: inhibitory ratio $=(1-$ average absorbance of treated group/average absorbance of control group) $\times 100$. $\mathrm{IC}_{50}$ was taken as the concentration that caused $50 \%$ inhibition of cell viability and was calculated by the Logit method.

\section{Annexin-V/PI staining}

A549 cells were harvested, washed, and resuspended in PBS after LZ-101 treatment, then stained with the Annexin-V/PI Cell Apoptosis Detection Kit (KeyGen Biotech, Nanjing, China) according to the manufacturer's instructions. Data acquisition and analysis were performed with a Becton Dickinson FACS Calibur flow cytometer using Cell-Quest software (BD Biosciences, Franklin Lakes, USA). The cells in early stages of apoptosis were Annexin- $\mathrm{V}$ positive and PI negative, whereas the cells in the late stages of apoptosis were both Annexin-V and PI positive.

\section{Mitochondrial transmembrane potential $\left(\Delta \Psi_{m}\right)$ assessment}

The electrical potential difference across inner membrane $\left(\Delta \Psi_{m}\right)$ was monitored using the $\Delta \Psi_{m}$-specific fluorescent probe JC-1 (Beyotime Institute of Biotechnology, Shanghai, China) $)^{34}$. The $\Delta \Psi_{\mathrm{m}}$-specific fluorescent probe JC-1 exists as a monomer with an emission at $530 \mathrm{~nm}$ (green fluorescence) at low membrane potential but forms J-aggregates with an emission at $590 \mathrm{~nm}$ (red fluorescence) at higher potentials. A549 cells were treated with LZ-101 for $24 \mathrm{~h}$. Cells were harvested and incubated with $\mathrm{JC}-1$ for $30 \mathrm{~min}$ at $37^{\circ} \mathrm{C}$ in the dark, then resuspended in washing buffer and relative fluorescence intensities were monitored using flow cytometry (FACSCalibur, Becton Dickinson, USA) with settings of FL1 (green) at $530 \mathrm{~nm}$ and FL2 (red) $585 \mathrm{~nm}$.

\section{Preparation of whole cell lysates and cytosolic and nuclear extracts}

A549 cells were treated with LZ-101 at indicated concentrations for $24 \mathrm{~h}$. The whole-cell lysates was prepared as described ${ }^{35}$. Nuclear and cytosolic protein extracts were prepared using a Nuclear/Cytosol Fractionation Kit (BioVision, Mountain View, CA) according to the manufacturer's protocol. The cytosolic and nuclear fractions were reserved for immunoblot analysis. Final detection was performed with western blots.

\section{Mitochondrial fractionation}

Mitochondrial fractionation kit (KeyGen Biotech, China) was used to get mitochondrial according to the following protocol. The cells were treated with different concentrations of LZ-101 for $24 \mathrm{~h}$ and $3.5 \times 10^{7}$ cells were incubated with $1 \mathrm{~mL}$ ice-cold mitochondrial lyses buffer, then suspended and ground the cells with tight pestle on ice. The homogenate was subjected to centrifugation at $800 \times g$ for $5 \mathrm{~min}$ at $4{ }^{\circ} \mathrm{C}$ to remove nuclei and unbroken cells, and then added $0.5 \mathrm{~mL}$ supernatant to the $0.5 \mathrm{~mL}$ Medium Buffer in the new $1.5 \mathrm{~mL}$ tube gently. After centrifugation at $15,000 \times g$ for $10 \mathrm{~min}$ at $4{ }^{\circ} \mathrm{C}$, the supernatant was carefully removed and collected as the cytosolic fraction and the remaining mitochondrial pellet was resuspended in the mitochondrial extraction buffer.

\section{Western blot analysis}

The whole cell lysates, cytosolic extracts, nuclear extracts, and mitochondrial extracts were prepared as described above. Western blot analysis was carried out as described previously ${ }^{35}$. Protein samples were separated by $10 \%$ SDS-PAGE and transferred onto nitrocellulose membranes. The membranes were incubated with $1 \%$ BSA at $37^{\circ} \mathrm{C}$ for $1 \mathrm{~h}$ and then indicated antibodies overnight at $4{ }^{\circ} \mathrm{C}$, followed by IRDye 800 conjugated secondary antibody for $1 \mathrm{~h}$ at $37^{\circ} \mathrm{C}$. Immunoreactive protein was detected with an Odyssey Scanning System (LI-COR Inc., Lincoln, Nebraska).

\section{Immunofluorescence microscopy}

For confocal imaging of fixed cells, A549 cells were used. After the appropriate treatment, cells were fixed with $4 \%$ paraformaldehyde in PBS, permeabilized with $0.5 \%$ Triton X-100, and blocked with 3\% BSA for $1 \mathrm{~h}$. Samples was incubated with primary antibodies (diluted 1:100) overnight at $4{ }^{\circ} \mathrm{C}$. After washed, Alexa Fluor 488 donkey anti-rabbit IgG, Alexa Fluor 594 donkey antirabbit IgG were used as secondary antibodies (Invitrogen, CA, USA). Samples were observed and captured with a confocal laser scanning microscope (Olympus Corp., Tokyo, Japan).

\section{Cell transfection}

GFP-LC3, mCherry-GFP-LC3 plasmid (Addgene, MA, USA), the siRNA targeting human FOXO3a, human ATG5, human ATG7 or control siRNA and the shRNA targeting human Bax or control shRNA with scrambled sequence were transfected using Lipofectamine $2000^{\mathrm{mi}}$ reagent (Invitrogen, CA, USA) according to the manufacturer's instructions. 


\section{Luciferase assay}

A549 cells were seeded in 6-well plate, cultured for $24 \mathrm{~h}$, and then transfected with $1 \mu \mathrm{g}$ pGMFOXO-Lu (Genomeditech, Shanghai, China) and $0.05 \mu \mathrm{g}$ pRL-TK Renilla (Beyotime, Nantong, China) with $10 \mu \mathrm{l}$ Lipofectamine 2000 and incubated for $24 \mathrm{~h}$ at $37^{\circ} \mathrm{C}$ with LZ-101. Cells were lysed with Promega passive lysis buffer and assayed by using Promega dual luciferase (Firefly luciferase/ Renilla luciferase) kit. Luciferase intensity was detected with a Luminoskan Ascent (Thermo Fisher Scientific Inc. Finland).

\section{Anti-tumor effects in nude mice}

Male BALB/c nude mice, 35-40 days old and with weight ranging from 18 to $22 \mathrm{~g}$, were supplied by Shanghai Laboratory Animal Limited Company. The mice were maintained in a pathogen-free environment $(23 \pm$ $2{ }^{\circ} \mathrm{C}$ and $55 \pm 5 \%$ humidity) on a $12 \mathrm{~h}$ light $-12 \mathrm{~h}$ dark cycle with food and water supplied ad libitum throughout the experimental period. Mice were subcutaneously inoculated with $1 \times 10^{6}$ A549 cells/nude mice. After 12-14 days, tumor sizes were determined using micrometer calipers, then nude mice with similar tumor volume (eliminate mice with tumors that are too large or too small) were randomly divided into four groups (6/group): one saline tumor control group; (i.v.) 5-fluorouracil $30 \mathrm{mg} / \mathrm{ml} / 2$ days group; (i.v.) LZ-101 $10 \mathrm{mg} / \mathrm{kg} / 2$ days group; (i.v.) LZ-101 $20 \mathrm{mg} / \mathrm{ml} / 2$ days group. At the end of 3 weeks, the mice were killed, and the tumor xenografts were removed and measured. Tumor volume (TV) was calculated using the following formula: $\mathrm{TV}\left(\mathrm{mm}^{3}\right)=d^{2} \times$ $D / 2$, where $d$ and $D$ are the shortest and the longest diameters, respectively. This study was approved in SPF Animal Laboratory of China Pharmaceutical University. Relative tumor volume (RTV) was calculated according to the equation: $\mathrm{RTV}=V_{t} / i_{0}$, where $V_{0}$ is the tumor volume at day 0 and $V_{t}$ is the tumor volume at day $t$. And the evaluation index for inhibition was of relative tumor growth ratio $\mathrm{T} / \mathrm{C}=\mathrm{TRTV} / \mathrm{CRTV} \times 100 \%$, where $\mathrm{TRTV}$ and CRTV represented RTV of treated and control groups, respectively.

\section{TUNEL assay}

Apoptosis induction in the tissue specimen was analyzed by TUNEL assay. It was performed as per instructions given in situ cell death kit. The slides were photographed with a confocal laser scanning microscope (Fluoview FV1000, Olympus, Tokyo, Japan).

\section{Immunohistochemistry}

The expression of FOXO3a, Bim, Bcl-2, Bax of the tissues of control and LZ-101 $(20 \mathrm{mg} / \mathrm{kg})$ treated groups was assessed by SP immunohistochemical method using a rabbit-anti-human monoclonal antibody and an Ultra-
Sensitive SP kit (kit 9710 MAIXIN, Fuzhou, Fujian). Tissue sections ( $4 \mathrm{~mm}$ thick) were placed onto treated slides (Vectabond, Vector Laboratories, Burlingame, CA). Sections were heat fixed, deparaffinized and rehydrated through graded alcohols $(100 \%, 95 \%, 85 \%$, and $75 \%)$ to distilled water. Tissue sections were boiled in citrate buffer at high temperature for antigen retrieval, and treated with 3\% hydrogen peroxide to block endogenous peroxidase activity. The slides were incubated with a protein-blocking agent (kit 9710 MAIXIN, Fuzhou, Fujian) prior to the application of the primary antibody, and then incubated with the primary antibody at $4{ }^{\circ} \mathrm{C}$ overnight. The tissues were then incubated with the secondary biotinylated anti-species antibody and labeled using a modification of the avidin-biotin complex immunoperoxidase staining procedure according to the UltraSensitive SP kit manual. Counterstaining was done with Harris hematoxylin. All reagents were supplied by MaixinBio Co. (Fuzhou, China).

\section{Statistical analysis}

All data in different experimental groups were expressed as mean \pm S.D. Data shown were obtained from at least three independent experiments. Statistical analysis was performed using an unpaired, two-tailed Student's $t$ test. All comparisons were made relative to untreated controls and significance of difference is indicated as ${ }^{*} p<$ 0.05 and $* * 00.01$.

\section{Author details}

${ }^{1}$ Department of Chemistry and Biochemistry, Florida International University, Miami, FL, USA. ${ }^{2}$ State Key Laboratory of Natural Medicines, Jiangsu Key Laboratory of Carcinogenesis and Intervention, China Pharmaceutical University, 24 Tongjiaxiang, 210009 Nanjing, The People's Republic of China. ${ }^{3}$ State Key Laboratory of Natural Medicines, Department of Natural Medicinal Chemistry, China Pharmaceutical University, 24 Tongjiaxiang, 210009 Nanjing, The People's Republic of China

Conflict of interest

The authors declare that they have no conflict of interest.

\section{Publisher's note}

Springer Nature remains neutral with regard to jurisdictional claims in published maps and institutional affiliations.

Received: 12 January 2019 Revised: 6 May 2019 Accepted: 30 May 2019 Published online: 19 June 2019

\footnotetext{
References

1. Buyukcelik, A., Yalcin, B. \& Utkan, G. Multidisciplinary management of lung cancer. N. Engl. J. Med. 350, 2008-2010 (2004).

2. Jemal, A. et al. Global cancer statistics. CA Cancer J. Clin. 61, 69-90 (2011).

3. Shi, L. et al. MiR-204 inhibits human NSCLC metastasis through suppression of NUAK1. Br J Cancer 111, 2316-2327 (2014).

4. Adams, J. M. \& Cory, S. The BCl-2 apoptotic switch in cancer development and therapy. Oncogene 26, 1324-1337 (2007).

5. Meng, J. et al. Apoptosis induction by MEK inhibition in human lung cancer cells is mediated by Bim. PLOS ONE 5, e13026 (2010).
} 
6. Zhang, L. N., Li, J. Y. \& Xu, W. A review of the role of Puma, Noxa and Bim in the tumorigenesis, therapy and drug resistance of chronic lymphocytic leukemia. Cancer Gene Ther. 20, 1-7 (2013).

7. Nordigarden, A. et al. BH3-only protein Bim more critical than Puma in tyrosine kinase inhibitor-induced apoptosis of human leukemic cells and transduced hematopoietic progenitors carrying oncogenic FLT3. Blood $\mathbf{1 1 3}$ 2302-2311 (2009).

8. Cragg, M. S., Kuroda, J., Puthalakath, H., Huang, D. C. \& Strasser, A. Gefitinibinduced killing of NSCLC cell lines expressing mutant EGFR requires BIM and can be enhanced by BH3 mimetics. PLoS Med. 4, 1681-1689 (2007).

9. Calnan, D. R. \& Brunet, A. The FoxO code. Oncogene 27, 2276-2288 (2008).

10. Yang, J. Y., Xia, W. \& Hu, M. C. Ionizing radiation activates expression of FOXO3a, Fas ligand, and Bim, and induces cell apoptosis. Int. J. Oncol. 29, 643-648 (2006).

11. Schmidt, M. et al. Cell cycle inhibition by FoxO forkhead transcription factors involves downregulation of cyclin D. Mol. Cell. Biol. 22, 7842-7852 (2002).

12. Medema, R. H., Kops, G. J., Bos, J. L. \& Burgering, B. M. AFX-like Forkhead transcription factors mediate cell-cycle regulation by Ras and PKB through p27kip1. Nature 404, 782-787 (2000).

13. Tran, $H$. et al. DNA repair pathway stimulated by the forkhead transcription factor FOXO3a through the Gadd45. Protein Sci. 296, 530-534 (2002).

14. Brunet, A. et al. Akt promotes cell survival by phosphorylating and inhibiting a Forkhead transcription factor. Cell 96, 857-868 (1999).

15. Qiang, W. et al. Proteasome inhibitor MG132 induces thyroid cancer cell apoptosis by modulating the activity of transcription factor FOXO3a. Endocrine 56, 98-108 (2017)

16. Fitzwalter, B. E. et al. Autophagy inhibition mediates apoptosis sensitization in cancer therapy by relieving FOXO3a turnover. Dev. Cell 44, 555-565 e553 (2018).

17. McGuirk, P. R. et al. Synthesis and structure-activity relationships of 7-diazabicycloalkylquinolones, including danofloxacin, a new quinolone antibacterial agent for veterinary medicine. J. Med. Chem. 35, 611-620 (1992).

18. Knoll, U., Glunder, G. \& Kietzmann, M. Comparative study of the plasma pharmacokinetics and tissue concentrations of danofloxacin and enrofloxacin in broiler chickens. J. Vet. Pharmacol. Ther. 22, 239-246 (1999).

19. Sappal, R., Chaudhary, R. K., Sandhu, H. S. \& Sidhu, P. K. Pharmacokinetics, urinary excretion and plasma protein binding of danofloxacin following intravenous administration in buffalo calves (Bubalus bubalis). Vet. Res. Commun. 33, 659-667 (2009).
20. Zhang, $X$. et al. Intranuclear localization of apoptosis-inducing factor (AIF) and large scale DNA fragmentation after traumatic brain injury in rats and in neuronal cultures exposed to peroxynitrite. J. Neurochem. 82, 181-191 (2002).

21. Zhao, Y. et al. Small molecule GL-V9 protects against colitis-associated colorectal cancer by limiting NLRP3 inflammasome through autophagy. Oncoimmunology 7, e1375640 (2017).

22. Nadja, S. et al. Microenvironmental autophagy promotes tumour growth. Nature 541, 417-420 (2017)

23. Yu, C. H. et al. Effect of danofloxacin on reactive oxygen species production, lipid peroxidation and antioxidant enzyme activities in kidney tubular epithelial cell line, LLC-PK1. Basic Clin. Pharmacol. Toxicol. 113, 377-384 (2013).

24. Rodriguez, J. \& Lazebnik, Y. Caspase-9 and APAF-1 form an active holoenzyme. Genes Dev. 13, 3179-3184 (1999).

25. Susin, S. A. et al. Molecular characterization of mitochondrial apoptosisinducing factor. Nature 397, 441-446 (1999).

26. Huang, D. C. \& Strasser, A. BH3-Only proteins-essential initiators of apoptotic cell death. Cell 103, 839-842 (2000).

27. Wang, X. The expanding role of mitochondria in apoptosis. Genes Dev. 15 2922-2933 (2001).

28. Puthalakath, H., Huang, D. C., O'Reilly, L. A., King, S. M. \& Strasser, A. The proapoptotic activity of the BCl-2 family member Bim is regulated by interaction with the dynein motor complex. Mol. Cell 3, 287-296 (1999).

29. Korsmeyer, S. J. et al. Pro-apoptotic cascade activates BID, which oligomerizes BAK or BAX into pores that result in the release of cytochrome c. Cell Death Differ. 7, 1166-1173 (2000).

30. Nechushtan, A., Smith, C. L., Lamensdorf, I., Yoon, S. H. \& Youle, R. J. Bax and Bak coalesce into novel mitochondria-associated clusters during apoptosis. J. Cell Biol. 153, 1265-1276 (2001).

31. Sundararajan, R. \& White, E. E1B 19K blocks Bax oligomerization and tumor necrosis factor alpha-mediated apoptosis. J. Virol. 75, 7506-7516 (2001).

32. Wei, M. C. et al. Proapoptotic BAX and BAK: a requisite gateway to mitochondrial dysfunction and death. Science 292, 727-730 (2001).

33. Dijkers, P. F., Medema, R. H., Lammers, J. W., Koenderman, L. \& Coffer, P. J. Expression of the pro-apoptotic BCl-2 family member Bim is regulated by the forkhead transcription factor FKHR-L1. Curr. Biol. 10, 1201-1204 (2000).

34. Tao, L. et al. LL-202, a newly synthesized flavonoid, inhibits tumor growth via inducing $\mathrm{G}(2) / \mathrm{M}$ phase arrest and cell apoptosis in MCF-7 human breast cancer cells in vitro and in vivo. Toxicol. Lett. 228, 1-12 (2014).

35. Qiang, L. et al. Inhibition of glioblastoma growth and angiogenesis by gambogic acid: an in vitro and in vivo study. Biochem. Pharmacol. 75, 1083-1092 (2008). 